\title{
Analisis Kinerja Angkutan Umum BMA (Studi Kasus Rute Pinrang - Makassar PP)
}

\author{
St. Maryam Hafran ${ }^{1}$, Mukhtar Thahir Syarkawi ${ }^{2}$, Ilham Syafei ${ }^{3}$, Ibnu Munsyir ${ }^{4}$, Samsu Saleh ${ }^{5}$ \\ 1,2,3,4,5 Program Studi Teknik Sipil Fakultas Teknik Universitas Muslim, Indonesia \\ Jl. Urip Sumoharjo KM 05 Makassar, Sulawesi Selatan \\ Email: ${ }^{1}$ stmaryam@umi.ac.id, ${ }^{2}$ mukhtartahir.sarkawi@umi.aci.id, ${ }^{3}$ Ilham.syafei@umi.ac.id, ${ }^{4}$ bennumunsyir@yahoo.co.id, ${ }^{5}$ samsu.saleh01@gmail.com
}

\author{
Kata kunci \\ Karakteristik \\ Penumpang, \\ Kinerja, Angkutan \\ Umum, BMA.
}

\begin{abstract}
Abstrak
Penelitian ini bertujuan untuk mengetahui karakteristik pengguna angkutan umum BMA Trans dan menganalisa kinerja angkutan umum BMA Trans rute pinrang-makassar PP. Penentuan ukuran sampel dalam penelitian ini dilakukan dengan menggunakan rumus Slovin.Setelah diuraikan validitas dan reliabitilas dari variabel pengukur dari masing-masing variabel laten, selanjutnya dijabarkan model structural dan model pengukuran. Olehnya itu berdasarkan uraian dan penjelasan kriteria model maka dapat dibentuk model, analisis model pengukuran dan model struktural. Hasil ini memberikan penjelasan bahwa kinerja pengguna angkutan terhadap kinerja angkutan BMA rute Pinrang-Makassar PP, memberikan kesimpulan bahwa faktor keandalan, keamanan dan ketepatan waktu menjadi ukuran untuk menggunakan atau menilai jasa angkutan BMA rute Pinrang-Makassar PP. Hasil survey kemudian diolah dengan menggunakan SEM pada Software SmartPLS 2.0 dan data yang diolah berupa keandalan, kenyamanan, keamanan, kemurahan dan ketepatan waktu, sehingga didapatkan secara komulatif kinerja angkutan umum khususnya BMA Trans. Untuk tingkat kenyamanan angkutan umum BMA tergolong sedang dengan nilai 23,25\%. Kemudian tingkat Kemurahan angkutan umum ini tergolong sangat tinggi dengan nilai $89,87 \%$.
\end{abstract}

\begin{abstract}
This study aims to determine the characteristics of BMA Trans public transport users and analyze the performance of BMA Trans public transport pinrang-Makassar PP routes. The determination of sample size in this study was carried out using the Slovin formula. After describing the validity and reliability of the measuring variables of each latent variable, the structural models and measurement models are then described. Therefore, based on the description and explanation of the model criteria, a model can be formed, analysis of measurement models and structural models. This result provides an explanation that the performance of transport users on the performance of BMA transport in the PinrangMakassar PP route gives a conclusion to use or assess BMA transportation services on the Pinrang-Makassar PP route. The survey results are then processed using SEM on SmartPLS 2.0 Software and the data processed is in the form of reliability, comfort, safety, generosity and timeliness, so that the cumulative performance of public transport is obtained, especially Trans BMA. For the comfort level of public transport BMA is classified as moderate with a value of $23.25 \%$. Then the level of merit of public transport is classified as very high with a value of $89.87 \%$.
\end{abstract}

\section{PENDAHULUAN}

Transportasi tidak dapat dipisahkan dari kehidupan umat manusia selama hal itu dibutuhkan dalam pendistribusian barang, pergerakan aktifitas manusia maupun barang sebagai komponen mikro suatu perekonomian. Pembangunan atau pengembangan sarana transportasi juga dapat menimbulkan dampak positif terhadap suatu wilayah (Fisu, 2018) dan di sisi lain pertumbuhan aktivitas ekonomi akan mempengaruhi permintaan terhadap transportasi yang lebih banyak (Fisu. 2019). Kegiatan transportasi harus dilakukan secara menyeluruh dengan keterpaduan fisik antar moda berupa titik simpul pertemuan antar moda (Humang. 2016). Sektor transportasi haruslah mampu memberikan kemudahan bagi seluruh masyarakat dalam segala kegiatan disemua lokasi yang berbeda dan tersebar dengan katakter fisik yang berbeda pula. Dengan semakin bertambahnya populasi manusia di sulawesi selatan makan akan berbanding lurus dengan kouta transportasi antar kota, dengan adanya salah satu instansi Transportasi BMA (Bintang Manunggal Abadi) ini sangat membantu Transportasi dalam propinsi dimana jumlah penumpang yang semakin membengkak saat ini dapat terpenuhi armada memadai dengan adanya BMA, selain mencerminkan 
keteraturan kota juga mencerminkan kelancaran kegiatan perekonomian kota. Oleh karena itu transportasi merupakan unsur yang sangat penting dan berfungsi sebagai urat nadi kehidupan dan perkembangan ekonomi, sosial dan politik dan mobilitas penduduk yang tumbuh bersamaan dan mengikuti perkembangan yang terjadi dalam berbagai dan sektor juga berperan sebagai perhubungan antar wilayah atau kota.

Dalam sejarah perkembangan manusia terhadap perkembangan kota dapat kita lihat bahwa manusia selalu berhasrat untuk berpergian dari satu tempat ke tempat lain guna mendapatkan keperluan yang dibutuhkan. Dalam hal ini manusia sangat membutuhkan sarana transportasi yang disebut moda atau angkutan. Kebutuhan akan pelayanan transportasi orang pada daerah perkotaan biasanya dilayani oleh angkutan umum (AU). Angkutan umum adalah angkutan penumpang dengan menggunakan kendaraan umum yang dilaksanakan dengan sistem sewa atau bayar. Peranan utama angkutan umum adalah melayani kepentingan mobilitas masyarakat dalam melakukan kegiatannya.

Kota Makassar merupakan salah satu kota terbesar di indonesia yang terus mengalami perkembangan yang pesat dari tahun ke tahun. Tingkat populasi penduduk di kota Makassar semakin meningkat tiap tahunnya. Sarana perndidikan yang lengkap, sarana kesehatan yang lebih baik, pusat-pusat perbelanjaan yang modern, bandar udara internasional, dan lain-lain merupakan suatu daya tarik bagi masyarakat dari wilayah lainnya untuk melakukan perjalanan dan menetap di Kota Makassar yang menjadikan penduduk Kota Makassar semakin padat. Kepadatan penduduk tersebut berimbas pada tingginya keinginan masyarakat untuk bepergian guna mendapatkan keperluan yang dibutuhkan, dan mayoritas masyarakat menggunakan angkutan umum sebagai sarana untuk bepergian.

Salah satu trayek angkutan umum antar kota dalam propinsi (AKDP) yang ada pada terminal Regional Daya adalah trayek Pinrang - Makassar PP. Jarak antara kota Makassar menuju kota Pinrang $\pm 182 \mathrm{~km}$. Mobilitas AU AKDP trayek Pinrang - Makassar PP terbilang padat diakibatkan tingginya permintaan penumpang untuk menggunakan AU AKDP trayek Pinrang - Makassar PP dengan alasan kepentingan yang beragam. Oleh karena itu pengelolaan moda angkutan Trayek Pinrang - Makassar PP pun semakin meningkat.

Terdapat beberapa jenis angkutan umum AKDP yang melayani Trayek Makassar - Pinrang PP mulai dari bus besar atau DAMRI. Mini Bus DAMRI dam Mobil Penumpang Umum (MPU) seperti APV, panther, kijang, avanza dan sejenisnya. Ada pula jenis kendaraan travel yang melayani Trayek Pinrang - Makassar PP yaitu mobil BMA. Setiap jenis AU Trayek Makassar-pinrang memiliki karakteristik yang berbeda mulai dari jenis kendaraan, harga kendaraan, jumlah kapasitas muat penumpang dan lain sebagainya.

\section{METODELOGI}

Metode penelitian pada dasarnya merupakan cara ilmiah untuk mendapatkan data dengan tujuan dan kegunaan tertentu. Secara umum data yang telah diperoleh dari penelitian dapat digunakan untuk memahami, memecahkan dan mengantisipasi masalah. Memahami berarti memperjelas suatu masalah atau informasi yang tidak diketahui dan selanjutnya menjadi tahu, memecahkan berarti meminimalkan atau menghilangkan masalah dan mengantisipasi berarti mengupayakan agar masalah tidak terjadi. Metode penelitian ini menggunakan metode penelitian deskriptif analitis yaitu penelitian yang bukan bersifat eksperimen dan dimaksudkan untuk mengumpulkan data-data yang dibutuhkan (berupa data primer dan data sekunder) yang berkaitan dengan penelitian, kemudian data-data tersebut akan dilanjutkan dengan proses analisis. Deskripsi berarti pemaparan (identifikasi) masalah-masalah yang ada, sedangkan analisis berarti data yang dikumpulkan mula-mula disusun, dijelaskan dan dianalisis. Inti dari metode penelitian ini adalah menguraikan bagaimana tata cara penelitian dilakukan. Pemilihan metode yang tepat sesuai dengan tujuan penelitian sangat berpengaruh pada cara-cara memperoleh data. Pengumpulan data harus dapat memenuhi tujuan penelitian sesuai dengan yang diharapkan.

Dari data kantor BMA Trans Kota Makassar tahun 2018 tercatat 16 unit jumlah mobil penumpang jenis angkutan umum BMA beroperasi per hari di 6 trayek yang menjangkau seluruh kawasan Sulawesi Selatan. Adapun rute, panjang rute dan jumlah armada yang beroperasi di Kota Makassar dapat dilihat pada tabel dibawah ini: 
Tabel 1. Kode Trayek, Nomor Polisi, Rute, Panjang Rute dan Jumlah Armada di Wilayah Sulawesi Selatan.

\begin{tabular}{|c|c|c|c|c|}
\hline No & Kode Trayek & Nomor Polisi & Rincian Jalur & Jarak \\
\hline \multirow{3}{*}{1} & BL 07 & DD 7334 RP & \multirow{3}{*}{$\begin{array}{l}\text { MAKASSAR - PINRANG } \\
\text { (Pergi-Pulang) }\end{array}$} & \multirow{3}{*}{ $\pm 182 \mathrm{~km}$} \\
\hline & BR 07 & DD 6518 AY & & \\
\hline & BR 25 & DD 7514 AY & & \\
\hline \multirow{3}{*}{2} & BC 02 & DD 7383 RP & \multirow{3}{*}{$\begin{array}{l}\text { PINRANG - MAKASSAR } \\
\text { ( Pergi-Pulang) }\end{array}$} & \multirow{3}{*}{ $\pm 182 \mathrm{~km}$} \\
\hline & BL 06 & DD 7226 RP & & \\
\hline & BP 07 & DD 7633 AY & & \\
\hline \multirow{3}{*}{3} & BL 08 & DD 7332 RP & \multirow{3}{*}{$\begin{array}{l}\text { MAKASSAR - BULUKUMBA } \\
\text { (Pergi-Pulang) }\end{array}$} & \multirow{3}{*}{ $\pm 150 \mathrm{~km}$} \\
\hline & BL 05 & DD 7237 AD & & \\
\hline & BR 20 & B 1567 CKX & & \\
\hline \multirow{3}{*}{4} & BR 24 & DD 7638 AY & \multirow{3}{*}{$\begin{array}{c}\text { BULUKUMBA-MAKASSAR } \\
\text { (Pergi-Pulang) }\end{array}$} & \multirow{3}{*}{ $\pm 150 \mathrm{~km}$} \\
\hline & BL 02 & DD 7513 AD & & \\
\hline & BR 22 & DD $7501 \mathrm{AY}$ & & \\
\hline \multirow{2}{*}{5} & BL 03 & DD 7526 AD & \multirow{2}{*}{$\begin{array}{c}\text { MAKASSAR - PARE-PARE } \\
\text { (Pergi-Pulang) }\end{array}$} & \multirow{2}{*}{ $\pm 135 \mathrm{~km}$} \\
\hline & BC 01 & DD $7351 \mathrm{R} 0$ & & \\
\hline \multirow{2}{*}{6} & BL01 & DD 7514 AD & \multirow{2}{*}{$\begin{array}{l}\text { PARE-PARE - MAKASSAR } \\
\text { (Pergi-Pulang) }\end{array}$} & \multirow{2}{*}{ $\pm 135 \mathrm{~km}$} \\
\hline & BR 26 & B 1566 CKX & & \\
\hline
\end{tabular}

Sumber : Kantor BMA trans Makassar 2018

\subsection{Sumber Data}

Sebelum melakukan suatu penelitian maka terlebih dahulu harus diketahui sumber data yang akan diteliti. Sumber data dalam suatu penelitian adalah subjek dimana suatu data dapat diperoleh. Penelitian ini menggunakan data berupa :

1) Data Primer

Data primer adalah data yang diperlukan untuk menjelaskan kinerja angkutan umum BMA rute Makassar-Pinrang. Data primer ini diperoleh melalui kegiatan:
a) Observasi, yaitu melakukan pengamatan langsung dilapangan, dalam hal ini melakukan perjalanan dengan angkutan umum BMA.
b) Kuesioner, yaitu memberikan sejumlah pertanyaan kepada responden yang dipandu oleh surveyor yang dilengkapi panduan lembaran kuesioner dengan alternative jawaban yang harus dipilih format jawaban untuk setiap kuesioner ialah tipe likert. Kuesioner didasarkan atas dimensi mutu pelayanan yang sifatnya umum (supranto, 2001).

2) Data Sekunder

Sumber data sekunder merupakan sumber data kedua diluar kata dan tindakan, namun data ini tidak diabaikan dan memiliki kedudukan penting. Data sekunder berupa sumber tertulis, majalah, surat kabar, buletin, jurnal dan hasil penelitian yang relevan. 


\subsection{Objek Penelitian}

Angkutan umum BMA yang kami jadikan sebagai objek penelitian ini. Penentuan ukuran sampel dalam penelitian ini dilakukan dengan menggunakan rumus Slovin sebagai berikut (Sugiyono : $2006: 57$ ) :

Dimana :

$$
n=\frac{N}{1+N e^{2}}
$$

$\mathrm{n}$ : Ukuran Sampel

$\mathrm{N}$ : Ukuran Populasi

e : Taraf kesalahan (error) sebesar 0,05 (5\%)

\subsection{Teknik Pengumpulan Data}

Metode pengumpulan data yang digunakan adalah wawancara, kuesioner, observasi maka alat pengumpulan datanya adalah:

a) Wawancara

Wawancara pada penelitian ini menggunakan interview berstruktur karena peneliti memandang ini adalah yang paling luwes, dimana subyek diberi kebebasan untuk menguraikan jawabannya dan ungkapan ungkapan pandangannya secara bebas dan sesuai harinya. Interview ini digunakan untuk mendapatkan data tentangkehandalan, daya tanggap, jaminan, empatidan bukti fisik angkutan umum antar kota dalam provinsi BMA di Sulawesi Selatan terhadap Masyarakat pengguna angkutan umum antar kota dalam provinsi BMA.

b) Kuesioner

Membagikan kuesioner yang berisi sejumlah pertanyaan kepada responden dan mewawancarai beberapa orang responden. Kuesioner merupakan sekumpulan pertanyaan yang diserahkan langsung kepada responden untuk diisi dan kemudian diserahkan kembali kepada peneliti. Ada dua tipe pengisian kuesioner, yaitu people assist dan self administered. Dalam penelitian ini, pengisian kuesioner menggunakan tipe people assist, dimana peneliti dapat memberi penjelasan mengenai pertanyaan yang kurang dipahami oleh responden dan menunggu sampai responden selesai mengisi kuesioner kemudian peneliti langsung mengumpulkan kuesioner yang telah diisi oleh responden.

Tujuan dasar dari penyediaan angkutan umum, Wells (1975) mengatakan, adalah menyediakan pelayanan angkutan yang baik -andal, nyaman, aman, cepat dan murah, untuk umum. Secara umum dapat dikatakan angkutan umum selalu kalah bersaing dengan kendaraan pribadi. Dari beberapa studi mengenai angkutan umum Harries (1976) menyatakan pelayanan angkutan umum dapat diusahakan mendekati angkutan pribadi untuk membuat angkutan umum menjadi lebih menarik dan pemakai angkutan pribadi tertarik berpindah ke angkutan umum.

Hal ini dapat diukur secara relatif dari kepuasan pelayanan. Beberapa kriteria angkutan umum ideal antara lain adalah:

a) Keandalan: setiap saat tersedia, kedatangan dan sampai tujuan tepat waktu, waktu total perjalanan singkat dari rumah, sedikit waktu berjalan kaki ke bus stop, tidak perlu berpindah kendaraan.

b) Kenyamanan: pelayanan yang sopan, terlindung dari cuaca buruk di bus stop, mudah turun naik kendaraan, tersedia tempat duduk setiap saat, tidak bersesak-sesak, interior yang menarik, tempat duduk yang enak.

c) Keamanan: terhindar dari kecelakaan, badan terlindung dari luka benturan, bebas dari kejahatan.

d) Kemurahan : Biaya berbanding lurus dengan fasilitas.

e) Ketepatan Waktu : waktu perjalanan sampai pada tujuan.

Kinerja angkutan umum BMA banyak dipengaruhi oleh faktor-faktor berikut:

a) Safety Meliputi keselamatan dalam berkendaraan (baik pengguna maupun bukan pengguna) dan pada hentian termasuk aman dari pencopetan dan kejahatan fisik juga keamanan kendaraan dari kekerasan (vandalism).

b) Comfort Meliputi kenyamanan fisik penumpang dalam kendaraan dan pada hentian. Kenyamanan ini antara lain: kualitas pengendaraan, lingkungan bus dan di luar bus, penataan kursi/berdiri, pegangan tangan, kemudahan keluar masuk dan pembayaran ongkos, tempat untuk barang bawaan seperlunya.

c) Estetika meliputi: kebersihan dan keindahan rancangan kendaraan, tempat-tempat hentian, terminal, trotoar yang menarik, perlindungan lingkungan (polusi udara/suara), fasilitas bagi manula dan kaum penyandang cacat atau disable, awak yang ramah dan menyenangkan. 


\subsection{Reliabilitas dan Validitas Data}

Untuk menjamin reliabilitas dan validitas untuk data kualitatif dapat dilakukan dengan berbagai cara. Menurut Creswell (2009) beberapa cara yang dapat digunakan untuk menjamin reliabilitas dan validitas data, yaitu: (1) triangulasi; (2) pengecekan oleh responden; (3) menggunakan deskripsi yang mendetail untuk memberikan pembaca gambaran mengenai nuansa suasana ketika wawancara dilakukan; (4) mengklarifikasi bias yang mungkin muncul dari pengumpulan data yang dilakukan. Pada penelitian ini cara yang digunakan adalah dengan triangulasi, yaitu dengan mengecek kesesuaian data yang diperoleh dari kuesioner (kuantitatif) dan wawancara (kualitatif), serta pengecekan oleh responden yaitu dengan meminta responden untuk mengkonfirmasi dan mengecek deskripsi yang dibuat oleh peneliti.

Reliabilitas dalam penelitian berkaitan dengan reliabilitas alar ukur dan hasil ukur, yaitu mengacu pada seberapa handal suatu alat atau hasil pengukuran bila dilakukan pengukuran ulang pada sampel yang berbeda (Azwar, 2010). Pada analisis data kuantitatif ini reliabilitas sampel diatasi dengan pengambilan sampel dalam jumlah yang besar (diatas 100). Jumlah sampel ini juga diharapkan dapat mengurangi kemungkinan terjadinya kesalahan sebab berdasarkan Teorema Limit Pusat dalam statistik, sampel dengan jumlah minimal 100 diasumsikan mempunyai distribusi yang normal (Healey 1995, 146). Reliabilitas dan validitas dari data kuantitatif yang diolah dengan metode statistika dapat diukur melalui koefisien reliabilitas dan koefisisen validitas sesuai dengan teknik analisis yang digunakan (Azwar, 2010). Pada penelitian ini reliabilitas dan validitas dari kuesioner sebagai alat pengumpulan data diuji melalui preliminary survei pada beberapa responden untuk mengetahui kesusaian antara maksud pertanyaan peneliti dan maksud yang ditangkap oleh responden.

\subsection{Kerangka Pemikiran}

Penelitian ini akan dimulai dengan pengumpulan data baik sekunder maupun data primer. Data primer diperoleh dengan penyebaran kuesioner, sedangkan data sekunder diperoleh dari majalah, surat kabar, bulletin, jurnal dan hasil penelitian yang relevan. Setelah memperoleh data-data tersebut, dilakukan analisis kinerja ditinjau dari segi efektifitas (keamanan dan kenyamanan dan kemurahan), dan efisiensi (keandalan dan ketepatan waktu). Dari hasil analisis tersebut kemudian dapat ditarik kesimpulan.Kerangka pikir dapat dilihat pada gambar bagan alir berikut:

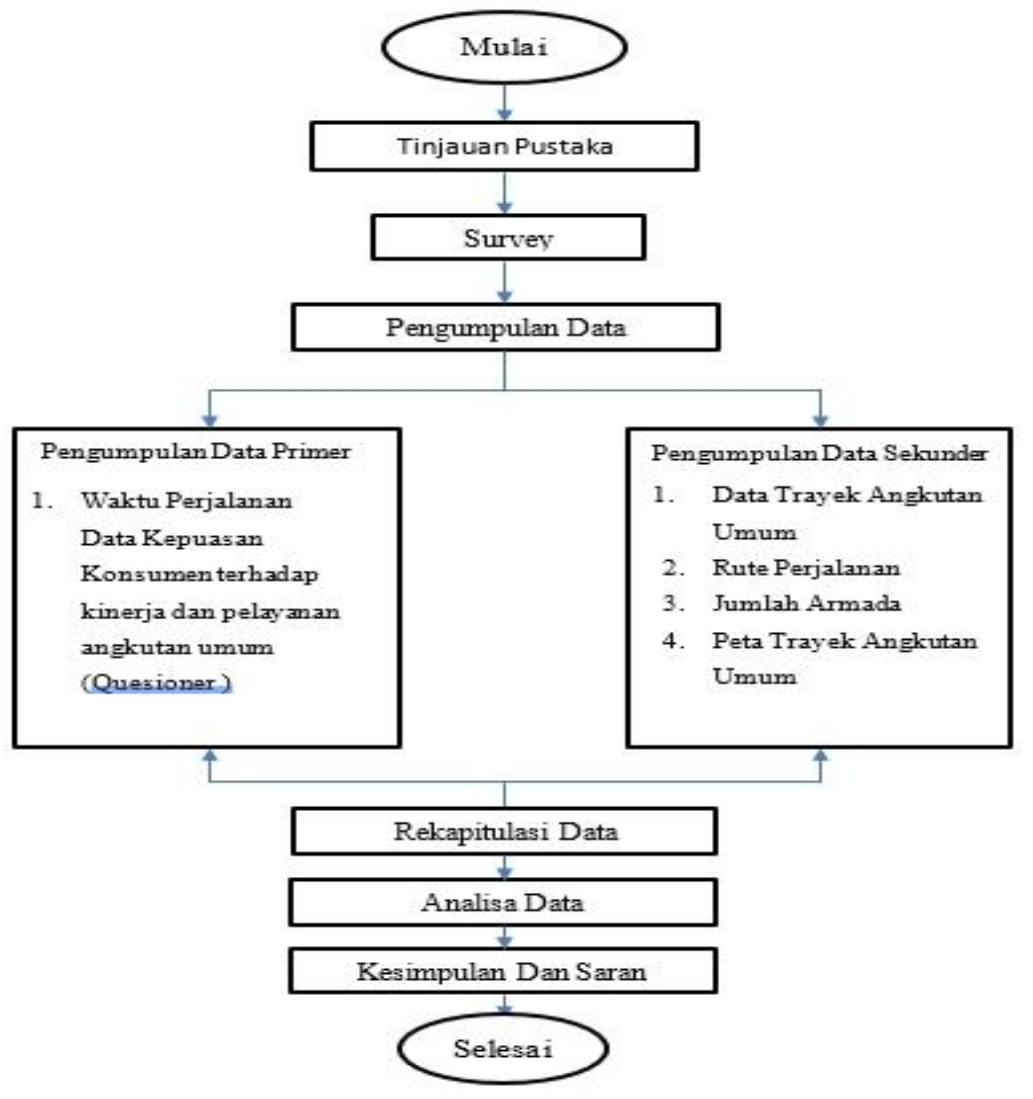

Gambar 1. Diagram Alir Kerangka Pikir 


\section{HASIL DAN PEMBAHASAN}

Pada penelitian ini penulis meneliti tentang penumpang yang menggunakan BMA Trans didalam melakukan aktifitasnya sehari-hari, untuk menggambarkan kondisi tersebut, berikut terlihat karakteristik pengguna BMA Trans :

Tabel 2. Gambaran Karakteristik Responden Angkutan Umum Berdasarkan Karakteristik Umum

\begin{tabular}{|c|c|c|c|}
\hline No. & Karakteristik Umum & $\begin{array}{c}\text { N } \\
\text { BMA Trans }\end{array}$ & $\begin{array}{c}\text { Persentase } \\
\text { BMA Trans } \\
\text { (\%) }\end{array}$ \\
\hline 1 & $\begin{array}{l}\text { Jenis Kelamin } \\
\text { a. Laki-laki } \\
\text { b. Perempuan }\end{array}$ & $\begin{array}{l}46 \\
66 \\
\end{array}$ & $\begin{array}{l}41 \% \\
59 \%\end{array}$ \\
\hline \multicolumn{2}{|r|}{ Total } & 112 & $100 \%$ \\
\hline 2 & $\begin{array}{l}\text { Umur } \\
\text { a. } 14-20 \text { Tahun } \\
\text { b. } 21-30 \text { Tahun } \\
\text { c. } 31-40 \text { Tahun } \\
\text { d. } \quad 41-50 \text { Tahun }\end{array}$ & $\begin{array}{l}13 \\
45 \\
35 \\
19\end{array}$ & $\begin{array}{l}12 \% \\
40 \% \\
31 \% \\
17 \%\end{array}$ \\
\hline \multicolumn{2}{|r|}{ Total } & 112 & $100 \%$ \\
\hline 3 & $\begin{array}{l}\text { Pekerjaan } \\
\text { a. PNS/Polri/TNI } \\
\text { b. Pegawai Swasta } \\
\text { c. Pelajar } \\
\text { d. Wiraswasta } \\
\text { e. Lainnya }\end{array}$ & $\begin{array}{l}10 \\
15 \\
11 \\
60 \\
16\end{array}$ & $\begin{array}{c}9 \% \\
14 \% \\
9 \% \\
54 \% \\
14 \% \\
\end{array}$ \\
\hline \multicolumn{2}{|r|}{ Total } & 112 & $100 \%$ \\
\hline 4 & $\begin{array}{l}\text { Pendidikan Terakhir } \\
\text { a. SMP } \\
\text { b. SMA } \\
\text { c. S1 }\end{array}$ & $\begin{array}{l}15 \\
50 \\
47\end{array}$ & $\begin{array}{l}13 \% \\
45 \% \\
42 \%\end{array}$ \\
\hline \multicolumn{2}{|r|}{ Total } & 112 & $100 \%$ \\
\hline 5 & \begin{tabular}{ll}
\multicolumn{2}{l}{ Tujuan Perjalanan } \\
a. & Bisnis/Bekerja \\
b. & Sekolah/Kuliah \\
c. & Belanja \\
d. & Rekreasi \\
e. & KunjunganKeluarga \\
\end{tabular} & $\begin{array}{c}50 \\
0 \\
25 \\
10 \\
27 \\
\end{array}$ & $\begin{array}{c}45 \% \\
0 \% \\
22 \% \\
9 \% \\
24 \% \\
\end{array}$ \\
\hline \multicolumn{2}{|r|}{ Total } & 112 & $100 \%$ \\
\hline 6 & $\begin{array}{l}\text { Frekuensi Menggunakan BMA } \\
\text { a. } 1-2 \mathrm{kali} / \mathrm{bulan} \\
\text { b. } 3-4 \mathrm{kali} / \mathrm{bulan} \\
\text { c. } 5 \mathrm{kali} / \mathrm{bulan} \\
\text { d. } 6-7 \mathrm{kali} / \mathrm{bulan} \\
\text { e. } 8 \mathrm{kali} / \mathrm{bulan}\end{array}$ & $\begin{array}{c}87 \\
20 \\
5 \\
0 \\
0 \\
\end{array}$ & $\begin{array}{c}78 \% \\
18 \% \\
4 \% \\
0 \% \\
0 \% \\
\end{array}$ \\
\hline \multicolumn{2}{|r|}{ Total } & 112 & $100 \%$ \\
\hline 7 & $\begin{array}{l}\text { Rata-rata Pendapatan } \\
\text { a. } 1 \text { Juta }-2 \text { Juta } \\
\text { b. } 2 \text { Juta }-3 \text { juta } \\
\text { c. } 3 \text { Juta }-4 \text { Juta } \\
\text { d. } 4 \text { Juta }-5 \text { Juta } \\
\text { e. } 5 \text { Juta }-6 \text { Juta }\end{array}$ & $\begin{array}{c}21 \\
43 \\
31 \\
14 \\
3\end{array}$ & $\begin{array}{l}19 \% \\
38 \% \\
27 \% \\
13 \% \\
3 \%\end{array}$ \\
\hline \multicolumn{2}{|r|}{ Total } & 112 & $100 \%$ \\
\hline
\end{tabular}




\section{Sumber: Data Primer, diolah}

\subsection{Analisis Hasil Penelitian}

Berdasarkan hasil penelitian yang diperoleh bahwa data dengan variabel laten endogen yaitu kinerja angkutan yang diukur melalui variabel laten eksogen yaitu Keandalan,Kenyamanan, Keamanan, Kemurahan, dan Ketepatan Waktu. Kelima variabel tersebut masing-masing memiliki indikator-indikator yang mempengaruhinya. Data yang diperoleh seperti pada lampiran penelitian ini, kemudian diolah dengan mengguanakan metode Partial Least Square (PLS) sebagai alat analisis dengan bantuan software SmartPLS $2.0 \mathrm{M} 3$.

\subsection{Validitas}

Uji validitas dilakukan dengan tujuan mengetahui ketepatan dan keandalan kuesioner yang mempunyai arti bahwa kuesioner mampu megukur apa yang seharunya diukur. Hasil dari uji ini cukup mencerminkan topik yang sedang diteliti. Uji validitas diuji dengan program SEM ( Structural Equation Modelling) dengan melihat korelasi Perasons's Product Moment untuk masing - masing item pernyataan dengan skor uji total.

Pengujian validitas dari setiap indikator yang mengukur setiap variabel laten Keandalan, Kenyamanan, Keamanan, Kemurahan, dan Ketepatan waktu serta Kinerja dilakukan dengan memperhatikan hasil analisis berdasarkan outer loading ( Measurement model) atau validitas konvergensi dari masing-masing konstruk.

Bambang W.O (2009) menyatakan bahwa nilai indikator loading faktor yang lebih besar sama dengan 0,5 dapat dikatan valid. Untuk memeriksa validitas konvergensi dari setiap indikator dapat memperhatikan tabel 4.3 berikut ini.

Tabel 3. Outer Model (Weights or Loadings)

\begin{tabular}{|c|c|c|c|c|c|c|}
\hline & $\mathrm{X1}$ & $\mathrm{X2}$ & $\mathrm{X3}$ & $\mathrm{X4}$ & $\mathrm{X5}$ & $\mathbf{Y}$ \\
\hline X1.1 & 0,980304 & & & & & \\
\hline $\mathrm{X} 1.3$ & 0,992336 & & & & & \\
\hline $\mathrm{X} 1.4$ & 0,979540 & & & & & \\
\hline $\mathrm{X} 2.2$ & & 0,989368 & & & & \\
\hline $\mathrm{X} 2.4$ & & 0,990253 & & & & \\
\hline X3.1 & & & 0,981880 & & & \\
\hline X3.2 & & & 0,975495 & & & \\
\hline X3.3 & & & 0,930514 & & & \\
\hline X3.4 & & & 0,976646 & & & \\
\hline X3.5 & & & 0,968200 & & & \\
\hline $\mathbf{X 4 . 1}$ & & & & 0,992884 & & \\
\hline $\mathrm{X} 4.2$ & & & & 0,990914 & & \\
\hline $\mathrm{X} 4.3$ & & & & 0,986472 & & \\
\hline X4.4 & & & & 0,987428 & & \\
\hline $\mathrm{X} 4.5$ & & & & 0,992017 & & \\
\hline X5.2 & & & & & 0,877376 & \\
\hline X5.3 & & & & & 0,776222 & \\
\hline X5.4 & & & & & 0,822963 & \\
\hline X5.5 & & & & & 0,776084 & \\
\hline Y1 & & & & & & 0,989920 \\
\hline Y2 & & & & & & 0,926466 \\
\hline Y3 & & & & & & 0,979826 \\
\hline Y4 & & & & & & 0,987153 \\
\hline Y5 & & & & & & 0,986810 \\
\hline
\end{tabular}

Sumber : Hasil Analisis SmartPLS 2.0 
Berdasarkan hasil analisis pada Table 3. di atas, menunjukan bahwa nilai loading factor untuk semua variable yang mengukur variable laten $>0,5$. Oleh karena itu, untuk variabel keandalan terlihat bahwa indicator X1.1, X1.3, X1.4 secara statistic signifikan atau valid dalam mengukur keandalan. Kemudian untuk variabel kenyamanan terlihat bahwa indicator X2.2, X2.4 secara statistik signifikan atau valid dalam mengukur kenyamanan, selanjutnya untuk variabel keamanan terlihat bahwa indikator X3.1, X3.2, X3.3, X3.4, X3.5 secara statistic signifikan atau valid dalam mengukur keamanan. Selanjutnya untuk variabel kemurahan terlihat bahwa indicator X4.1, X4.2, X4.3, X4.4, X4.5 secara statistic signifikan atau valid dalam mengukur kemurahan dan untuk variabel ketepatan waktu terlihat bahwa indicatorX5.2, X5.3, X5.4, X5.5 secara statistic signifikan atau valid dalam mengukur variabel ketepatan waktu. Selanjutnya untuk variabel kinerja angkutan terlihat bahwa indicator Y1, Y2, Y3, Y4, Y5 secara statistic signifikan atau valid dalam mengukur kinerja angkutan. Hasil tersebut sejalan dengan nilai statistic.

Struktural Equation Modeling (SEM)

Analisis Model Penelitian

a) Model Pengukuran

Model pengukuran adalah model yang membangun hubungan antara variable laten dengan indicatorindikatornya.

Dimana :

$$
\begin{aligned}
& X 1=0,336 X_{11}+0,334 X_{13}+0,335 X_{14}+\delta_{1} \\
& X 2=0,494 X_{22}+0,516 X_{24}+\delta_{2} \\
& X 3=0,249 X_{31}+0,175 X_{32}+0,261 X_{33}+0,166 X_{34}+0,184 X_{35}+\delta_{3} \\
& X 4=0,200 X_{41}+0,202 X_{42}+0,203 X_{43}+0,200 X_{44}+0,203 X_{45}+\delta_{4} \\
& X 5=0,373 X_{52}+0,195 X_{53}+0,301 X_{54}+0,275 X_{55}+\delta_{5} \\
& Y=0,209 Y_{1}+0,195 Y_{2}+0,206 Y_{3}+0,208 Y_{4}+0,206 Y_{5}+\varepsilon
\end{aligned}
$$

$\mathrm{X}=$ Konstruk variabel laten eksogen

$\mathrm{Y}=$ Konstruk variabel laten endogen

$\lambda=$ Nilai outer wiight indikator

\begin{tabular}{|c|c|c|c|c|c|}
\hline $\begin{array}{l}\text { Variabel } \\
\text { laten }\end{array}$ & Indikator & Nilai outer weght & $\begin{array}{l}\text { Original } \\
\text { Sample } \\
(\text { O) }\end{array}$ & $\begin{array}{c}\text { T Statistics } \\
\text { (|O/STERR|) }\end{array}$ & Keterangan \\
\hline \multirow{3}{*}{ Keandalan } & $\mathrm{X} 1.1<-\mathrm{X1}$ & 0,980304 & 0,336596 & 170,112408 & Signifikan \\
\hline & $\mathrm{X} 1.3<-\mathrm{X} 1$ & 0,992336 & 0,344407 & 130,270487 & Signifikan \\
\hline & $\mathrm{X} 1.4<-\mathrm{X1}$ & 0,979540 & 0,335123 & 162,104001 & Signifikan \\
\hline \multirow{2}{*}{ Kenyamanan } & $\mathrm{X} 2.2<-\mathrm{X} 2$ & 0,989368 & 0,494215 & 201,020273 & Signifikan \\
\hline & $X 2.4<-X 2$ & 0,990253 & 0,516070 & 102,831364 & Signifikan \\
\hline \multirow{5}{*}{ Keamanan } & X3.1 <- X3 & 0,981880 & 0,249017 & 1,376694 & Signifikan \\
\hline & $\mathrm{X3.2<- \textrm {X3 }}$ & 0,975495 & 0,175204 & 0,798362 & Signifikan \\
\hline & $\mathrm{X} 3.3<-\mathrm{X3}$ & 0,930514 & 0,261036 & 1,120448 & Signifikan \\
\hline & X3.4 <- X3 & 0,976646 & 0,166703 & 0,932697 & Signifikan \\
\hline & $\mathrm{X3.5<-} \mathrm{X3}$ & 0,968200 & 0,184752 & 1,787311 & Signifikan \\
\hline \multirow{5}{*}{ Kemurahan } & X4.1 <- X4 & 0,992884 & 0,200654 & 290,020466 & Signifikan \\
\hline & $X 4.2<-X 4$ & 0,990914 & 0,202040 & 275,035189 & Signifikan \\
\hline & $X 4.3<-X 4$ & 0,986472 & 0,203322 & 191,008513 & Signifikan \\
\hline & X4.4<- X4 & 0,987428 & 0,200478 & 247,198362 & Signifikan \\
\hline & $X 4.5<-X 4$ & 0,992017 & 0,203665 & 189,460312 & Signifikan \\
\hline Ketepatan & X5.2<- X5 & 0,877375 & 0,373030 & 12,314659 & Signifikan \\
\hline
\end{tabular}

$\mathrm{x}=$ Nilai outer loadings indikator

$\mathrm{y}=$ Nilai outer loadings indikator

$\delta=$ Standard error variabel laten

$\varepsilon=$ Nilai Redundancy

Tabel 4. Nilai Outer Weight 


\begin{tabular}{|c|c|c|c|c|c|}
\hline \multirow{7}{*}{ waktu } & $\mathbf{X 5 . 3}<-\mathbf{X 5}$ & 0,776222 & 0,271480 & 7,874138 & Signifikan \\
\cline { 2 - 6 } & $\mathbf{X 5 . 4}<-\mathbf{X 5}$ & 0,822963 & 0,301494 & 7,791437 & Signifikan \\
\cline { 2 - 6 } & $\mathbf{X 5 . 5}<-\mathbf{X 5}$ & 0,776084 & 0,275570 & 6,639026 & Signifikan \\
\hline \multirow{4}{*}{ Kinerja } & Y1 <- Y & 0,989920 & 0,208952 & 133,707098 & Signifikan \\
\cline { 2 - 6 } & Y2 <- Y & 0,926466 & 0,195318 & 103,515057 & Signifikan \\
\cline { 2 - 6 } & $\mathbf{Y 3 ~ < - ~ Y ~}$ & 0,979826 & 0,206891 & 152,607817 & Signifikan \\
\cline { 2 - 6 } & $\mathbf{Y 4 < - ~ Y ~}$ & 0,987153 & 0,208258 & 138,774402 & Signifikan \\
\cline { 2 - 6 } & $\mathbf{Y 5}<-\mathbf{Y}$ & 0,986810 & 0,206625 & 145,444664 & Signifikan \\
\hline
\end{tabular}

Pada tabel 4. terlihat bahwa nilai T-statistik untuk nilai outer weight indicator-indikator pada semua variable laten diatas 1,96. Hal ini menunjukkan bahwa indikator-indikator tersebut secara signifikan memberikan kontribusi dalam mengukur variable latennya masing-masing.

Dan berdasarkan hasil pada tebel 4.20 maka didapatkan hasil dari penjumlahan terhadap setiap variabel laten terhadap indicator masing-masing yaitu X1 $=0.988, \mathrm{X} 2=0.999, \mathrm{X} 3=0.998, \mathrm{X} 4=0.994, \mathrm{X} 5=0.886$ dan $\mathrm{Y}=0.997$.

b) Model Struktural

Model structural adalah model yang mendeskripsikan hubungan yang linier dan memiliki kualitas antar variable laten. Persamaan model structural penelitian ini dapat dituliskan seperti berikut:

$$
Y=-0,114 X 1+0,232 \times 2-0,002 X 3+0,898 \times 4+0,006 \times 5+\zeta
$$

Tabel 5. Koefisien Jalur Model Struktural

\begin{tabular}{|c|c|c|c|c|}
\hline & Koefisien jalur & $\begin{array}{c}\text { Original } \\
\text { Sample (O) }\end{array}$ & $\begin{array}{c}\text { T Statistics } \\
\text { (|O/STERR|) }\end{array}$ & $\begin{array}{c}\text { Latent } \\
\text { Variable } \\
\text { Corelation }\end{array}$ \\
\hline X1 -> Y & $\mathrm{X} 1$ & $-0,114696$ & 1,036960 & 1 \\
\hline $\mathrm{X} 2$-> Y & $\mathrm{X} 2$ & 0,232569 & 10,379905 & 0,881048 \\
\hline X3 -> Y & $\mathrm{X} 3$ & 0,002755 & 0,249670 & 0,12397 \\
\hline X4 -> Y & $\mathrm{X} 4$ & 0,898762 & 8,308402 & 0,990755 \\
\hline X5 > Y & $\mathrm{X} 5$ & 0,006993 & 0,750356 & $-0,40918$ \\
\hline \multicolumn{4}{|c|}{$\mathbf{Y}$} & 0,978141 \\
\hline
\end{tabular}

Sumber : hasil analisis SmartPLS 2.0

Pada table 4.20 memperlihatkan bahwa variabel eksogen yaitu variabel Y (kinerja), serta lima variabel endogen yaitu variabel X1(Keandalan), X2 (kenyamanan), X3 (Keamanan), X4 (kemurahan) dan X5 (ketepatan waktu). Nilai koefisien jalur (X1)menunjukkan tidak ada pengaruh positif variabel (Kinerja) terhadap (Keandalan), nilai koefisien jalur (X2) menunjukkan adanya pengaruh positif variabel (Kinerja) terhadap (Keamanan), nilai koefisien jalur (X3) menunjukkan tidak ada pengaruh positif variabel (Kinerja) terhadap (Keamanan), nilai koefisien jalur (X4) menunjukkan adanya pengaruh positif variabel (Kinerja) terhadap (kemurahan), nilai koefisien jalur (X5) menunjukkan tidak ada pengaruh positif variabel (Kinerja) terhadap (Ketepatan waktu). Adapun nilai $(\zeta$ ) menunjukkan pengaruh variabel lain selain terhadap variable yang diteliti. 


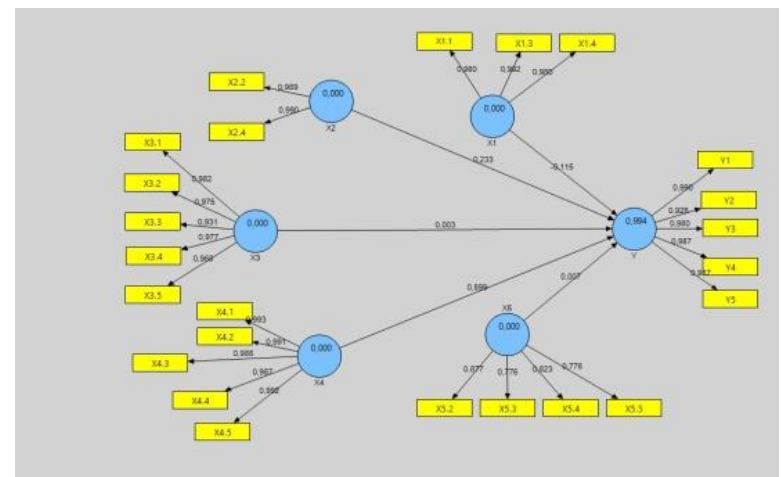

Gambar 2. Diagram jalur hasil output smart PLS.

Tabel 4.22 Hasil pengujian Hipotesis

\begin{tabular}{|l|c|c|c|c|}
\hline & $\begin{array}{c}\text { T Statistics } \\
(\mid \mathbf{O} / \text { STERR|) }\end{array}$ & T table & Ho & $\begin{array}{c}\text { Pengaruh terhadap } \\
\text { variabel ( X dan Y ) }\end{array}$ \\
\hline $\mathbf{X 1 ~ - > ~ Y ~}$ & 1,200312 & 1,95 & Gagal Ditolak & Tidak Signifikan \\
\hline $\mathbf{X 2}$-> Y & 11,298365 & 1,95 & Ditolak & Signifikan \\
\hline $\mathbf{X 3 ~ - > ~ Y ~}$ & 0,273787 & 1,95 & Gagal Ditolak & Tidak Signifikan \\
\hline $\mathbf{X 4}$-> Y & 9,252808 & 1,95 & Ditolak & Signifikan \\
\hline $\mathbf{X 5}$-> Y & 0,788936 & 1,95 & Gagal Ditolak & Tidak Signifikan \\
\hline
\end{tabular}

Hasil ini memberikan penjelasan bahwa kinerja pengguna angkutan terhadap kinerja angkutan BMA rute Pinrang-Makassar PP, memberikan kesimpulan bahwa faktor keandalan, keamanan dan ketepatan waktu menjadi ukuran untuk menggunakan atau menilai jasa angkutan BMA rute Pinrang-Makassar PP.

\section{KESIMPULAN}

\subsection{Kesimpulan}

Berdasarkan hasil penelitian yang telah dilakukan, maka diperoleh:

1. Karakteristik pengguna angkutan umum BMA umumnya lebih banyak di gunakan oleh penumpang berjenis kelamin perempuan dengan persentase sebanyak 59\%, usia 21-30 tahun dengan persentase $40 \%$, berprofesi sebagai wiraswasta dengan persentase $54 \%$, memliki pendidikan terakhir SMA dengan persentase $45 \%$, tujuan perjalanan yaitu Bisnis/Bekerja dengan persentase $45 \%$, menggunakan angkutan umum hanya 1-2 kali/bulan dengan persentase $78 \%$, pendapatan rata-rata 2.000.000 - 3.000.000.

2. Kinerja Angkutan BMA :

a) Dalam masalah keandalan, keamanan dan ketepatan waktu bagi para penumpang tidaklah mempersoalkannyakarena mendapatkan hasil yang positif dari hasil penelitian.

b) Tetapi dalam hal kenyamanan dan kemurahan dari hasil penelitian pada bab IV menunjukkan bahwa para penumpang mempersoalkan masalah kenyamanan dan kemurahan.

\subsection{Saran}

1. Sebaiknya pelayanan angkutan umum BMA perlu ditingkatkan kembali dari sektor kenyamanan.

2. Untuk meningkatkan kinerja angkutan umum BMA sebaiknya operator kendaraan diberi peringatan untuk terus memperhatikan kebersihan dari angkutan menjaga agar penumpang nyaman didalamnya,juga sebaiknya pihak BMA Trans menurunkan harga dan memantau terus keadaan armada demi menjaga kenyamanan penumpang.

3. Cara penanganan dalam upaya meningkatkan kinerja yang lebih efisien dan efektif dimasa yang akan datang yaitu :

a) Perlu adanya fasilitas yang di adakan untuk menunjang kenyamanan bagi para penumpang BMA Trans seperti interior di dalam mobil bersih dan enak di pandang dan juga harga tiketnya untuk tidak terlalu melangit.

b) Dalam masalah harga dari BMA termasuk mahal pada persepsipenumpang maka dari itu perlunya kesetaraan harga dengan fasilitas. 


\section{DAFTAR PUSTAKA}

Aksan Sofyan (2004), Kinerja Angkutan Umum Kota Makassar, (Studi Kasus Angkutan Umum Penumpang Pete-Pete), Universitas Hasanuddin.

Fisu AA. (2018). Analisis Kebutuhan Fasilitas Sisi Laut Pelabuhan terminal Khusus PLTGU Lombok. PENA TEKNIK: Jurnal Ilmiah Ilmu-ilmu Teknik Vol 3 No 2, 197 - 206.

Fisu AA. (2019). Tinjauan Kecelakaan lalu Lintas Antar Wilayah Pada Jalan Trans Provinsi Sulawesi Selatan. PENA TEKNIK: Jurnal Ilmiah Ilmu-ilmu Teknik Vol 4 No 1, 53 - 65.

Herry Lubis, Julaihi Wahid, Rahmad Dian (2005), Persepsi Pelaku Perjalanan Terhadap Pelayanan Angkutan Umum Di Kota Medan, Universitas Sumatera Utara.

Humang Windra Priatna \& Zulfadly. (2016). Analisis Keterpaduan Moda Transportasi Angkutan Penyeberangan dangan Jalan Raya di pelabuhan bajoe Kab. Bone. PENA TEKNIK: Jurnal Ilmiah Ilmu-ilmu Teknik Vol 1 No 1, 27 - 38.

PopyRufaidah (2010), Persepsi Penumpang Jasa Transportasi Angkutan Umum Atas Kewajaran Harga, Universitas Padjadjaran.

Sigit Haryono (2010), Analisis Kualitas Pelayanan Angkutan Umum (Bus Kota) Di Kota Yogyakarta, UPN Yogyakarta.

Novian Herbowo (2012), Studi Persepsi Pengguna Transjakarta Pada Koridor II, (Pulogadung-Harmoni). UNJ Jakarta.

Hajerah (2017), Analisis Persepsi Pengguna Terhadap Kinerja Angkutan Umum Di Makassar. Universitas Muslim Indonesia Makassar 